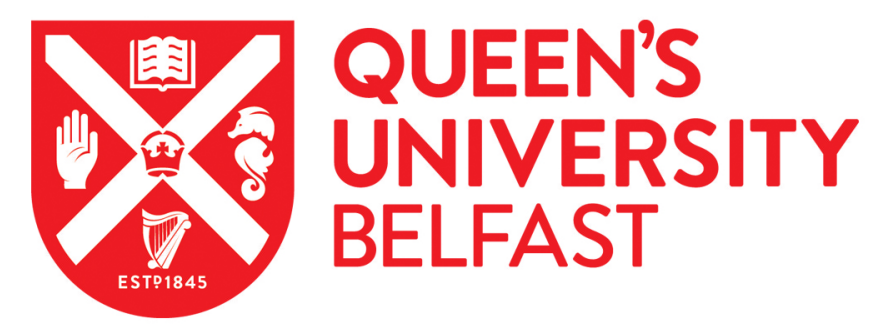

\title{
Alcohol, smoking and the risk of premalignant and malignant colorectal neoplasms
}

Fagunwa, I. O., Loughrey, M. B., \& Coleman, H. G. (2017). Alcohol, smoking and the risk of premalignant and malignant colorectal neoplasms. Best Practice \& Research: Clinical Gastroenterology, 31, 561-568.

https://doi.org/10.1016/j.bpg.2017.09.012

Published in:

Best Practice \& Research: Clinical Gastroenterology

Document Version:

Peer reviewed version

Queen's University Belfast - Research Portal:

Link to publication record in Queen's University Belfast Research Portal

\section{Publisher rights}

Copyright 2017 Elsevier Ltd.

This manuscript is distributed under a Creative Commons Attribution-NonCommercial-NoDerivs License

(https://creativecommons.org/licenses/by-nc-nd/4.0/), which permits distribution and reproduction for non-commercial purposes, provided the author and source are cited.

\section{General rights}

Copyright for the publications made accessible via the Queen's University Belfast Research Portal is retained by the author(s) and / or other copyright owners and it is a condition of accessing these publications that users recognise and abide by the legal requirements associated with these rights.

Take down policy

The Research Portal is Queen's institutional repository that provides access to Queen's research output. Every effort has been made to ensure that content in the Research Portal does not infringe any person's rights, or applicable UK laws. If you discover content in the Research Portal that you believe breaches copyright or violates any law, please contact openaccess@qub.ac.uk. 
Title: Alcohol, smoking and the risk of premalignant and malignant colorectal neoplasms

Authors: Ifewumi O. Fagunwa ${ }^{1}$, BSc, Maurice B. Loughrey ${ }^{2,3}$, BSc, MRCP, FRCPath, MD, and Helen G. Coleman ${ }^{1}$, BSc, PhD.

\section{Affiliations:}

${ }^{1}$ Cancer Epidemiology Research Group, Centre for Public Health, Queen's University Belfast, Northern Ireland, United Kingdom.

${ }^{2}$ Department of Histopathology, Belfast Health and Social Care Trust, Northern Ireland, United Kingdom.

${ }^{3}$ Centre for Cancer Research and Cell Biology, Queen's University Belfast, Northern Ireland, United Kingdom.

Emails: $\quad$ ifagunwa01@qub.ac.uk; maurice.loughrey@belfasttrust.hscni.net; h.coleman@qub.ac.uk

Corresponding author: Dr Helen G Coleman, PhD, Centre for Public Health, Queen's University Belfast, ICS-B Building, Royal Victoria Hospital Site, Grosvenor Rd, Belfast, Northern Ireland, BT12 6BJ. Tel: + 44 2890978953; Fax: +44 28 90235900; Email: h.coleman@qub.ac.uk

Role of the funding source: Ifewumi Fagunwa was funded by a Summer Studentship at the Centre for Public Health, Queen's University Belfast. Helen Coleman is a co-investigator of the Centre of Excellence for Public Health, Northern Ireland. These funding sources did not have any role in the collection, analysis and interpretation of data and in the writing of the manuscript.

Conflict of interest statement: None.

Word Count: 6,484 words. 


\begin{abstract}
Colorectal cancer (CRC) is the third most common cancer worldwide and has a complex aetiology consisting of environmental and genetic factors. In this review, we evaluate the roles of alcohol and tobacco smoking in colorectal neoplasia. Alcohol intake and tobacco smoking are associated with modest, but significantly, increased risks of CRC, adenomatous and serrated polyps. There is consistent evidence of doseresponse relationships for both alcohol and smoking, and risk of these neoplasms. Alcohol and smoking appear to be more strongly associated with colorectal polyp than CRC development, suggesting roles in the initiation of neoplastic growths. These lifestyle factors also seem more strongly related to adenomas and sessile serrated lesions than hyperplastic polyps, but further confirmation is required. The gastroenterology community has an important, yet currently underexploited, role to play addressing the modifiable factors associated with CRC and polyps. These behaviours include, but are not limited to, alcohol and smoking.
\end{abstract}

\title{
Keywords
}

Serrated polyps; Colorectal adenomas; Colorectal cancer; Cancer risk; Epidemiology 
Colorectal cancer (CRC) is a multifactorial disease of complex aetiology encompassing both genetic and environmental factors [1]. It arises from the gradual accumulation of pathogenic mutations in normal colonic mucosa [1,2]. Approximately $95 \%$ of CRCs are classified as adenocarcinomas, which originate in the colorectal mucous-producing glands [1]. Other types of CRC are rare [3].

\section{Pathogenesis of colorectal neoplasms (A)}

CRC is initiated when mutations result in the malignant transformation of preneoplastic polyps $[1,4]$. In the past, adenomas and hyperplastic polyps were considered to be the two main subgroups of epithelial colorectal polyps $[2,5]$. Adenomas were regarded as the sole precursor lesions of CRC whilst hyperplastic polyps were believed to possess no malignant potential $[5,6]$. This hypothesis has since been partially negated, and the umbrella term 'serrated polyp' is now used to encompass benign hyperplastic polyps, as well as sessile serrated lesions and traditional serrated adenomas, with the latter two forms of serrated polyp both considered to harbour neoplastic potential [7] (Figure 1). Conventional adenomas and serrated polyps are morphologically distinct, arising from two genetically and epigenetically different pathways with unique clinical manifestations $[8,9]$.

\section{Adenoma-carcinoma sequence (B)}

Adenomatous polyps can progress to $\mathrm{CRC}$ via the traditional pathway known as the adenoma-carcinoma sequence, which refers to a classical stepwise molecular progression from normal colorectal mucosa, through dysplasia and ultimately to invasive adenocarcinoma $[10,11]$. The inactivation of the adenomatous polyposis coli 
(APC) tumour suppressor gene leads to oncogene activation, and is key to adenoma development [12].

Serrated polyp-carcinoma pathway $(B)$

Serrated polyps provide an alternative pathway to CRC via the serrated polypcarcinoma pathway, which is estimated to account for between $10 \%$ and $30 \%$ of CRCs [9]. Abnormal DNA methylation is key to the development of this type of CRC [13].

Histologically, the characteristic feature of serrated polyps is infolding of the crypt epithelium, producing a stellate appearance in cross-section and a saw-toothed or serrated appearance in longitudinal section [14]. Endoscopically, hyperplastic polyps and sessile serrated lesions have a similar, pale, appearance and their boundaries with the surrounding normal mucosa are often not clearly demarcated [15]. They differ however in size and site, with sessile serrated lesions commonly larger and more proximally located than hyperplastic polyps.

\section{Epidemiology of colorectal cancer (A)}

Colorectal cancer is the third most common cancer worldwide [16], accounting for more than $9.7 \%$ of all cancer incidence in 2012 [17]. Each year, almost 1.4 million new cases are diagnosed, making CRC a major cause of morbidity and mortality globally [18] and the fourth most common cause of cancer death [16]. The highest age-standardised incidence rates have been recorded in Australia, New Zealand, Canada, the United States (US) and parts of Europe [18] (Figure 2). 
However, CRC incidence rates appear to be stabilising in many high-income settings [19], which may in part reflect improved early detection through screening programmes and prevention through polypectomy [16]. A decline in mortality from $\mathrm{CRC}$ in these regions can also be attributed to improvements in treatments including radiotherapy and chemotherapy [20,21]. Conversely, CRC incidence and mortality is quickly rising in several medium-to-high Human Development Index countries with this trend being particularly notable in parts of Eastern Europe, Asia and South America [16]. On the basis of projected demographic changes, the World Health Organization expects an increase in the global burden of CRC, with an estimated 77\% increase in newly diagnosed CRC cases and an $80 \%$ increase in CRC deaths by 2030 $[1,22,23]$.

It is therefore important to clarify the role of modifiable risk factors, such as alcohol consumption and tobacco smoking, in CRC development, in order to identify preventative strategies that could reduce this projected increase in CRC burden.

\section{Risk factors for colorectal cancer (B)}

A small proportion (approximately 5\%) of $\mathrm{CRC}$ is attributable to known genetic predisposition syndromes, such as familial adenomatous polyposis and Lynch syndrome (formerly known as hereditary non-polyposis colorectal cancer) [24,25]. Individuals with chronic idiopathic inflammatory bowel disease (chronic ulcerative colitis or Crohn's disease) are also at an increased risk of CRC compared with the general population, although actual risk is still low - for example, an estimated $0.8 \%$ of patients with chronic ulcerative colitis develop CRC each year [26]. 
Colorectal cancer is also associated with a number of modifiable risk factors and it has been estimated that between $66 \%$ and $75 \%$ of CRC cases are preventable $[1,18,27]$. A number of studies have associated aspects of a western lifestyle, such as obesity, physical inactivity and high red-meat consumption, with increased CRC risk $[28,29]$.

In their 2011 report (due to be updated in 2017), the World Cancer Research Fund/American Institute for Cancer Research (WCRF/AICR) judged the strength of evidence for a number of risk factors associated with CRC [30]. This report found 'convincing' evidence that both physical activity and foods containing dietary fibre decrease CRC risk, whilst red meat, processed meat, body fatness, abdominal fatness, and adult attained height were all associated with an increased risk of developing CRC [30]. Furthermore, the WCRF/AICR report stated that it is 'probable' that a decreased risk of CRC is associated with high intakes of garlic, milk and calcium. The WCRF/AICR report did also judge that alcoholic drinks increase the risk of CRC, but reported convincing evidence in men and only probable evidence of this association in women [30].

There is also evidence that non-steroidal anti-inflammatory drugs, aspirin [31,32], and hormone replacement therapy in postmenopausal women decrease CRC risk [33,34]. For the purposes of this review, we focus on evaluating the evidence investigating alcohol consumption, tobacco smoking and risk of CRC and colorectal polyps, respectively. It is worth highlighting that the majority of studies described utilise self-report measures of alcohol intake and smoking, which are often subject to 
response biases, and so the following evidence summary may reflect underestimates of associations between these lifestyle factors and colorectal neoplasia.

\section{Alcohol and colorectal cancer risk (A)}

The association between alcohol and colorectal neoplasia risk is summarised in Table 1. In 2007, a working group for the International Agency for Research on Cancer (IARC) reviewed epidemiological evidence from over 50 studies that reported on the association of alcohol consumption and 27 anatomical sites including the colon/rectum [35]. IARC concluded that there was sufficient evidence to support the addition of $\mathrm{CRC}$ to the list of malignancies causally related to alcohol [36,37]. As outlined above, this association has also been confirmed by the 2011 WCRF/AICR report on CRC risk factors [30]. A further analysis conducted in 2015 has combined results from 2 cohort studies and 22 case-control studies, and revealed that the pooled relative risk (RR) of $\mathrm{CRC}$ for any drinkers in comparison with non-drinkers and occasional drinkers is 1.13 (95\% confidence interval (CI), 1.09-1.17) [38].

There is also consistent evidence of a dose-response association between alcohol and CRC risk [38-40]For light, moderate and heavy drinking (defined as $\leq 1,2-3$ and $\geq 4$ drinks/day, respectively), the RR were 1.07 (95\% CI, 1.02-1.13), 1.23 (95\% CI, 1.15-1.32) and 1.37 (95\% CI, 1.26-1.49), respectively [38]. Meta-regression analysis within the same study confirmed the presence of a significant, direct, dose-response relationship between alcohol intake and CRC risk [38]. Similar findings were noted in previous research that estimated that compared to occasional and non-drinkers, individuals that consume at least 4 drinks a day are 52\% more likely to develop CRC 
[39]. Subgroup analyses within studies have also found similar increased risks for higher alcohol consumption across tumor sites (i.e. colon or rectum) $[38,40]$.

The biological plausibility of a dose-response relationship is supported by an in vitro study on genotoxicity of ethanol and acetaldehyde on gastrointestinal tract mucosa cells. Blasiak et al identified a dose-dependent increase in breaks in colonic mucosa DNA strands with ethanol exposure [41]. Acetaldehyde has also been implicated in folate degradation [3] which can lead to chromosome breakage and misappropriation of uracil [42]. This is a key underlying mechanism by which alcohol is thought to promote colorectal carcinogenesis.

\section{Alcohol, age at onset, and colorectal cancer risk (B)}

Regular alcohol consumption has also been implicated in the development of CRC at a younger age, and is associated with distal location of these tumours [43]. Recently, there has been concern over rising $\mathrm{CRC}$ incidence in adults aged under 50 years, which has been particularly notable for rectal cancers [44-46]. In analysis of 161,172 CRC patients comparing self-reported current (within the past year), past (quit at least 1 year prior to diagnosis) and never drinkers of alcohol revealed that were was a lower age of onset for CRC amongst alcohol drinkers [43]. Amongst CRC cases, current and past use of alcohol was linked to being diagnosed, on average, 5.2 and 2.1 years younger than never drinkers with $\mathrm{CRC}$ diagnosis $(P<.001$ for both). However, this study was somewhat limited by their categorization of 'past drinker', which is likely to be a heterogeneous group [43]. Further research is required to determine if changing patterns of alcohol and other lifestyle factors, such as obesity, may be contributing to the overall observed decline in CRC age at onset [45]. 
Alcohol types and colorectal cancer risk (C)

Existing evidence for beverage-specificity with regard to CRC risk is inconsistent [47-49]. The European Prospective Investigation into Cancer and Nutrition-Norfolk (EPIC-Norfolk) study demonstrated a significant inverse association between daily consumption of one glass of wine and overall CRC risk with a hazard ratio (HR) of 0.61 (95\% CI: $0.40-0.94)$ [49]. The risk with wine was postulated to be to be lower in rectal cancers than in colon cancers, although this may have been a consequence of the small number of rectal cases within this study. Similar findings were observed in a subsequent study, which identified a borderline significant inverse association between wine consumption (1-5 glasses per week) and CRC (HR 0.86 (95\% CI: $0.73-$ 1.01)) [48]. Again, the association appeared to be stronger in rectal cancers (HR 0.62 , 95\% CI: 0.47-0.83) [48]. Existing literature does indicate that wine has anticarcinogenic and protective properties for other cancers, which may explain the inverse relationship observed between light-moderate wine intake and CRC [50-52].

In the EPIC study, beer intake was also associated with a significant $38 \%$ increased risk of CRC (HR 1.38, 95\% CI 1.08-1.77 for 20-39.9 vs. 0.1-2.9 g/day) [49]. Spirits and liquor were associated with non-significant increased risk of rectal cancers only (1.27, 95\%CI 0.96-1.69 for $>5 \mathrm{~g} /$ day vs. $0.1-1.9 \mathrm{~g} /$ day) [49].

Overall, it is very difficult to distinguish alcohol types when advising patients and the general public about their alcohol consumption, with specific regards to CRC prevention. The WCRF/AICR recommend that individuals limit their alcohol intake 
and follow national guidelines, if consumed at all, but advise against alcohol consumption for purposes of cancer prevention [53].

\section{Alcohol and colorectal polyp risk (A)}

When evaluating evidence for polyp risk, it is crucial to consider study designs. Due to the asymptomatic nature of many colorectal polyps, it is important that controls (i.e. individuals without polyps) in such studies have had the opportunity for a polyp to be diagnosed i.e. that all underwent an endoscopy. For a number of studies reporting on alcohol, smoking and polyp risk, the sole method of assessment for the colon was sigmoidoscopy, as opposed to a full colonoscopy. Therefore, risk of proximal rightsided adenomas and serrated polyps often cannot be estimated. Additionally, unlike

CRC outcomes, general cohort studies are not appropriate, and only case-control or nested case-control studies within cohort/trial participants who undergo endoscopy, can truly assess polyp outcomes. This in turn has consequences for recall bias, and likely underreporting of alcohol/smoking behaviours in case-control studies that may underestimate true associations with colorectal polyp risk.

\section{Alcohol and colorectal adenoma risk (B)}

The association between alcohol consumption and risk of colorectal adenomas has been investigated in several observational studies. A meta-analysis of 23 case-control studies and 2 nested case-control studies within cohorts compared all drinkers to nondrinkers, and found summative RRs of colorectal adenoma were 1.17 (95\% CI 1.111.22) in case-control studies and 1.08 (95\% CI 0.88-1.33) in the nested case-control studies, respectively [54]. 
Again, a dose-response relationship between alcohol and colorectal adenomas was observed, demonstrating that individuals who consumed 10, 25, 50 and $100 \mathrm{~g}$ of alcohol per day, had RRs of developing colorectal adenoma of 1.02 (95\% CI 0.89 1.16), 1.06 (95\% CI $0.92-1.20), 1.16$ (95\% CI $1.02-1.33)$ and 1.61 (95\% CI $1.42-$ 1.84), respectively, compared with occasional and non-drinkers [54]. This association was consistent for both males and females [54]. The link did, however, appear to be stronger in European studies compared to those conducted in Asia or the US [54]. This may be a reflection of variations in screening guidelines, as well as due to genetic factors. In keeping with previous meta-analyses of CRC [39,54], risk of colorectal adenoma did not differ according to different anatomical sites of the colon and rectum [54].

Alcohol and serrated polyp risk (B)

Alcohol has also been linked with an increased risk of serrated polyps. A recent meta-analysis of studies comparing high versus low alcohol consumption with regard to serrated polyp development revealed a significant increased risk of overall serrated polyps (RR 1.33; 95\% CI, 1.17-1.52) [2]. The magnitude of this increased risk was found to be greater for sessile serrated lesions (also known as sessile serrated adenomas/polyps) (RR 1.85; 95\% CI, 1.03-3.32), but still evident for hyperplastic polyps (RR, 1.30; 95\% CI, 1.15-1.48) [2]. The meta-analysis was slightly limited by many studies reporting on hyperplastic polyp outcomes potentially including some sessile serrated lesions that were misclassified as benign hyperplastic polyps. Therefore further research is required in studies that carefully review and distinguish these serrated polyp subtypes, in order to confirm the stronger influence of alcohol on sessile serrated lesions compared with hyperplastic polyps. 


\section{Smoking and colorectal cancer risk (A)}

The association between smoking and colorectal neoplasia risk is summarised in Table 2. Tobacco smoke is a well established carcinogen, and research confirms that there is a significant association between smoking and CRC risk. Large, multicentre cohort studies and meta-analyses have demonstrated that this association is present for both past and current smokers [55,56]. Results indicate a significant $38 \%$ increased CRC risk in current smokers (RR, 1.38; 95\% CI, 1.22-1.56), while former smokers have an $18 \%$ increased risk of CRC (RR, 1.18; 95\% CI, 1.12-1.25), compared with never smokers [56]. Although former smokers still experience this increased CRC risk compared with never smokers, the reduced magnitude of the association compared with current smokers indicates some evidence of a benefit for smoking cessation in reducing CRC risk.

Dose-response effects of smoking have also been clearly demonstrated when considering tobacco exposure as number of years smoking, total number of packyears or the number of cigarettes consumed daily [56,57]. Individuals who have smoked for $<30$ pack-years have an estimated $19 \%$ increased CRC risk, while those who smoked for $\geq 30$ pack-years have a $28 \%$ increased CRC risk, compared with never-smokers [56]. This has also been quantified as a $6 \%$ increased CRC risk per additional 5 years pack-years of smoking [58]. A meta-analysis of 11 studies has also identified modest, but significant, increased risks of CRC associated with passive smoking [59]. Overall though, it is notable that the magnitude of the increased CRC risk associated with smoking is much lower than that seen for upper gastrointestinal cancers $[60,61]$. A review published in JAMA has estimated that tobacco smoking 
contributes an absolute risk of 11 additional CRC cases per 100,000 person years of follow-up [57].

As with alcohol, the role for smoking in colorectal neoplasia is biologically plausible. Tobacco smoke is inundated with carcinogens such as aromatic amines, nitrosamines, heterocyclic amines and polycyclic aromatic hydrocarbons [62]. Following metabolism by the cytochrome P450 system, these compounds can lead to the production of abnormal DNA and mutations in genes implicated in CRC such as KRAS and BRAF [63], the latter of which is particularly prevalent in serrated colorectal neoplasms.

\section{Smoking, location and molecular subtypes of colorectal cancer risk (B)}

There appears to be consistent evidence that tobacco smoking is more strongly associated with both rectal and right-sided colon cancer risk, compared with left-sided colon cancers $[62,63]$. In their meta-analysis, Cheng et al reported increased CRC risks in smokers compared with non-smokers, but identified $24 \%$ and $9 \%$ increases for rectal versus colon cancers, and greater risks for proximal versus distal colon cancers (summary RRs 1.31; 95\% CI, 1.13-1.52; and 0.98, 95\% CI, 0.84-1.14, respectively, $p=0.03$ ) [64]. It will therefore be useful for studies to ascertain whether there are different pathogenic mechanisms underlying colonic and rectal cancers. An overall stronger association between smoking and CRC in males compared with females has also been hypothesised to occur as a result of divergent patterns of chromosomal mutations $[56,65,66]$.

A comprehensive systematic review of smoking history, molecular pathways and CRC risk has found that smoking is associated with tumours that are P53 and/or 
BRAF mutant, demonstrate high microsatellite instability (MSI-high) and are CIMP positive, but smoking was not implicated in the aetiology of APC or KRAS mutant CRC [67]. Furthermore, smoking has also been associated with increased risks of synchronous CRC that are MSI-high, CIMP positive or BRAF mutant [68]. Collectively, this suggests stronger involvement of tobacco smoking in the colorectal serrated pathway, compared with the adenoma-carcinoma sequence.

\section{Smoking and colorectal polyp risk (A)}

Smoking and Colorectal adenoma risk (B)

Studies consistently report that there is a significantly greater proportion of colorectal adenomas amongst smokers compared with non-smokers [69,70]. A meta-analysis of 42 observational studies demonstrated pooled risk estimates for colorectal adenoma in current, former and ever smokers of 2.14 (95\% CI, 1.86-2.46), 1.47 (95\% CI, 1.291.67), and 1.82 (95\% CI, 1.65-2.00), respectively [69]. Again, clear dose-response associations between smoking and adenoma risk have been noted [70].

Disparities in the effects of smoking on the risk of developing a colorectal adenoma appears to be more pronounced in men than in women, with a risk at low smoking exposure (defined as $\leq 15$ pack-years of smoking) being solely apparent in men [70]. It has been hypothesized that hormone replacement therapy [71,72] and higher prevalence of calcium supplement use among women, which both have protective effects against adenoma development, may explain these differences [73].

Smoking and serrated polyp risk (B) 
Smoking is commonly cited as a risk factor for serrated polyps and this association has been further clarified in a meta-analysis of 29 studies published in 2017 [2]. A 2.5 fold increased serrated polyp risk was identified when comparing individuals with the highest to the lowest smoking exposure [2]. Although the risk was apparent for serrated polyps overall, there was a stronger association for sessile serrated lesions (RR, 3.40; 95\% CI, 1.90-6.07) in comparison with hyperplastic polyps (RR, 2.34; 95\% CI, 2.00-2.73) [2].

Although there is a strong body of evidence to support an association between smoking and the development of serrated polyps, the evidence on anatomical location of these is inconsistent. A study that included pooled data obtained from three large multi-centre chemoprevention trials showed that there was a link between smoking and the development of serrated polyps in the distal colon (RR 2.18; 95\% CI 1.80 2.65) but not the proximal colon (RR $1.11 ; 95 \%$ CI $0.80-1.54$ ) [74]. These findings were corroborated in a case-control study in which, when non-smokers and current smokers were compared, no association was found between tobacco use and the development of proximal serrated polyps [75]. Similar to alcohol, further studies in which serrated polyps have been characterised according to current histological classification, and all participants have undergone full colonoscopy, would help to further clarify the magnitude of associations between smoking and risk of serrated polyp subtypes.

\section{Interventional studies addressing alcohol, smoking and colorectal neoplasia (A)}

For numerous health reasons beyond the association with CRC and colorectal polyps, individuals should be advised not to smoke tobacco. Advice regarding alcohol 
consumption is less straightforward but, generally, individuals should be advised to limit their intake if they consume alcohol. Although there are some nuances that deserve further study in observational settings, such as accurately quantifying the association between lifestyle factors and serrated polyp subtypes, or age at CRC onset, it is timely now for gastroenterological research to place greater attention on lifestyle interventions in order to reduce CRC burden.

Overall, it is noteworthy that associations between alcohol and smoking appear to be stronger for colorectal polyp risk than CRC development (Tables 2 and 3). This could reflect limitations in study designs of polyp risk, that often require cross-sectional assessment of lifestyle habits, however, it may also point towards greater biological roles of alcohol and smoking in the initiation of neoplastic growths. The diagnosis of pre-malignant colorectal polyps in an individual offers a valuable opportunity for a 'teachable moment' in which to promote healthier lifestyle choices that include responsible alcohol consumption and being smoke-free. In this regard, the entire gastroenterology community has an important, but currently underexploited, role to play.

Trials of lifestyle behaviours and polyp risk to date have (appropriately) not focussed specifically on smoking cessation or alcohol intake, likely due to the lower impact of these factors on risk compared with, for example, nutrition. The Polyp Prevention Trial in the US has sought to intervene to reduce recurrence in almost 2,000 individuals who had been diagnosed with colorectal adenomas [76]. That intervention did not specifically target alcohol and smoking behaviours, but required individuals to adhere to a very strict low-fat, high-fibre, high fruit and vegetable diet. 
A 35\% reduced odds of adenoma recurrence was observed amongst 'super' compliers to the intervention, demonstrating the success of a targeted intervention amongst this patient group [76]. A more recent intervention conducted in Scotland (the BeWEL intervention), has sought to aid weight loss and increase physical activity amongst 329 individuals who had a colorectal adenoma diagnosis [77]. The BeWEL intervention has achieved successful weight loss outcomes, but the impact on future colorectal neoplasia risk is, as yet, unclear [77]. Both trials demonstrate the success of using this time (a colorectal adenoma diagnosis) and clinical setting to address behaviour change. It would be interesting to conduct future health service interventions that incorporate alcohol and smoking lifestyle advice, to evaluate the impact on outcomes detected at follow-up colonoscopies. These may be delivered by signposting individuals to supporting services, such as smoking cessation clinics or pharmacies [78], or be in the form of 'brief intervention' advice [79,80], due to time constraints in the clinical gastroenterology setting.

\section{Summary (A)}

There is a large body of evidence to support the role of both alcohol and smoking in colorectal neoplasia. Alcohol intake is associated with significantly increased risks of CRC, adenomatous and serrated polyps, and there is evidence of a dose-response relationship. These trends appear to be consistent across both genders and different anatomical sites within the colorectum. With regards to smoking, there is a modest but significant increased risk of CRC and colorectal polyps, and again a doseresponse relationship has been identified, compared with never smokers. There are however gender differences and differences in risk according to anatomical sub-site, with greater risks for male smokers and for proximal colon and rectal tumours. There 
is also evidence of smoking influencing risk of distinct molecular subtypes of CRC, most notably BRAF, P53 mutant and MSI-high and CIMP-positive tumours. Overall, alcohol and smoking appear to be more strongly associated with risk of colorectal polyps than CRC, per se. The diagnosis of colorectal polyp offers an opportune moment for gastroenterologists and the supporting health professional team to signpost individuals to smoking cessation services or offer advice on alcohol consumption as part of broader health promotion, as appropriate. Further molecular pathology epidemiology studies and interventional studies are warranted in this area. 


\section{Practice points}

- Tobacco smoking and higher alcohol intake are associated with modest, but significant, increased risks of colorectal polyps and cancer

- There is evidence that smoking is particularly implicated in the serrated colorectal pathway, and specific molecular subtypes of colorectal cancers

- Individuals diagnosed with colorectal polyps should be offered appropriate lifestyle advice, that includes information on responsible alcohol consumption and smoking cessation, where appropriate

\section{Research agenda}

- With a few exceptions, such as the suggestions below, the era of observational studies for alcohol, smoking and colorectal polyp and cancer risk has now largely passed, due to conclusive findings that these contribute to increased risks of these neoplasms. Interventional studies addressing alcohol and smoking (and other) lifestyle behaviours are now required, particularly amongst individuals diagnosed with colorectal polyps.

- The role of lifestyle factors, including alcohol and smoking, in the recent increase in CRC incidence in younger adults requires further investigation.

- Quantifying the association between alcohol, smoking and serrated polyp subtypes requires further research in studies with standardised and current pathological reporting, to clarify potentially stronger associations for sessile serrated lesions than benign hyperplastic polyps.

- Molecular pathology epidemiology research studies are required to fully explore the association between alcohol, smoking and colorectal neoplasms according to different molecular characteristics. 


\section{References}

1. Binefa G, Rodríguez-Moranta F, Teule A \& Medina-Hayas M. Colorectal cancer: from prevention to personalized medicine. World J Gastroenterol 2014;20:6786-808.

2. *Bailie L, Loughrey MB \& Coleman HG. Lifestyle Risk Factors for Serrated Colorectal Polyps: a Systematic Review and Meta-analysis. Gastroenterology 2017;152:92-104

3. Marley AR \& Nan H. Epidemiology of colorectal cancer. Int J Mol Epidemiol Genetics 2016;7:105-14.

4. Muto T, Nagawa H, Watanabe T, Masaki T \& Sawada T. Colorectal carcinogenesis: historical review. Dis Colon Rectum. 1997;40(10 Suppl):S80-5.

5. Kim SW, Cha JM, Lee J Il, Joo KR, Shin HP, Kim GY, et al. Significant number of sessile serrated adenomas might not be accurately diagnosed in daily practice. Gut Liver 2010;4:498-502.

6. Goldstein NS. Serrated pathway and APC (conventional)-type colorectal polyps: Molecular-morphologic correlations, genetic pathways, and implications for classification. Am J Clin Pathol 2006;125;146-53

7. Noffsinger AE. Serrated Polyps and Colorectal Cancer: New Pathway to Malignancy. Annu Rev Pathol Mech Dis 2009;4:343-64.

8. Sakai E, Fukuyo M, Ohata K, Matsusaka K, Doi N, Mano Y, et al. Genetic and epigenetic aberrations occurring in colorectal tumors associated with serrated pathway. Int J Cancer 2016;138:1634-44.

9. Patai AV, Molnár B \& Tulassay ZS. Serrated pathway: Alternative route to colorectal cancer. World J Gastroenterol 2013;19:607-15.

10. Leslie A, Carey FA, Pratt NR \& Steele RJ. The colorectal adenoma-carcinoma 
sequence. Br J Surg 2002;89:845-60

11. Armaghany T, Wilson JD, Chu Q \& Mills G. Genetic alterations in colorectal cancer. Gastrointest Cancer Res 2012;5:19-27.

12. Erhardt JG, Kreichgauer HP, Meisner C, Bode JC \& Bode C. Alcohol, cigarette smoking, dietary factors and the risk of colorectal adenomas and hyperplastic polyps--a case control study. Eur J Nutr 2002;41:35-43.

13. Dong SM, Lee EJ, Jeon ES, Park CK \& Kim KM. Progressive methylation during the serrated neoplasia pathway of the colorectum. Mod Pathol 2005;18:170-8.

14. Leggett B \& Whitehall V. Role of the Serrated Pathway in Colorectal Cancer Pathogenesis. Gastroenterology 2010;138:2088-100.

15. Saito S, Tajiri H \& Ikegami M. Serrated polyps of the colon and rectum: Endoscopic features including image enhanced endoscopy. World J Gastrointest Endosc 2015;7:860-71.

16. *Arnold M, Sierra MS, Laversanne M, Soerjomataram I, Jemal A \& Bray F. Global patterns and trends in colorectal cancer incidence and mortality. Gut 2017;66:683-691.

17. Siegel R, Desantis C \& Jemal A. Colorectal Cancer Statistics, 2014. CA Cancer J Clin 2014;64:104-17.

18. Haggar FA \& Boushey RP. Colorectal cancer epidemiology: Incidence, mortality, survival, and risk factors. Clin Colon Rectal Surg 2009;22:191-7.

19. Jemal A, Center MM, DeSantis C \& Ward EM. Global patterns of cancer incidence and mortality rates and trends. $\underline{\text { Cancer Epidemiol Biomarkers Prev }}$ 2010;19:1893-907.

20. Center MM, Jemal A \& Ward E. International trends in colorectal cancer 
incidence rates. Cancer Epidemiol Biomarkers Prev 2009;18:1688-94.

21. Murphy CC, Harlan LC, Lund JL, Lynch CF \& Geiger AM. Patterns of Colorectal Cancer Care in the United States: 1990-2010. J Natl Cancer Inst 2015;107(10).

22. Karsa L V., Lignini TA, Patnick J, Lambert R \& Sauvaget C. The dimensions of the CRC problem. Best Pract Res Clin Gastroenterol 2010;24:381-96.

23. Stewart BW, Wild CP. World cancer report 2014. International Agency for Research on Cancer Report. 2014;1-2. Available at: http://publications.iarc.fr/Non-Series-Publications/World-CancerReports/World-Cancer-Report-2014

24. Da Silva FC, Wernhoff P, Dominguez-Barrera C \& Dominguez-Valentin M. Update on hereditary colorectal cancer. Anticancer Research 2016;36:4399405

25. Stoffel EM \& Boland CR. Genetics and Genetic Testing in Hereditary Colorectal Cancer. Gastroenterology 2015;149:1191-203.

26. Fumery M, Dulai PS, Gupta S, Prokop LJ, Ramamoorthy S, Sandborn WJ, et al. Incidence, Risk Factors, and Outcomes of Colorectal Cancer in Patients With Ulcerative Colitis With Low-Grade Dysplasia: A Systematic Review and Metaanalysis. Clin Gastroenterol Hepatol 2017;15:665-674.e5.

27. Johnson IT \& Lund EK. Nutrition, obesity and colorectal cancer. Aliment Pharmacol Ther 2007;26: 161-81.

28. Bishehsari F, Mahdavinia M, Vacca M, Malekzadeh R \& Mariani-Costantini R. Epidemiological transition of colorectal cancer in developing countries: Environmental factors, molecular pathways, and opportunities for prevention. World J Gastroenterol 2014;20:6055-72. 
29. Stigliano V, Sanchez-Mete L, Martayan A \& Anti M. Early-onset colorectal cancer: A sporadic or inherited disease? World J Gastroenterol 2014;20:12420 30.

30. *World Cancer Research Fund / American Institute for Cancer Research. Continuous Update Project Report. Food, Nutrition, Physical Activity, and the Prevention of Colorectal Cancer. 2011. Available at: http://www.wcrf.org/int/research-we-fund/continuous-update-project-findingsreports/colorectal-bowel-cancer

31. Dulai PS, Singh S, Marquez E, Khera R, Prokop LJ, Limburg PJ, et al. Chemoprevention of colorectal cancer in individuals with previous colorectal neoplasia: systematic review and network meta-analysis. BMJ 2016;355.

32. Ye X, Fu J, Yang Y \& Chen S. Dose-Risk and Duration-Risk Relationships between Aspirin and Colorectal Cancer: A Meta-Analysis of Published Cohort Studies. PLoS One 2013;8(2).

33. Green J, Czanner G, Reeves G, Watson J, Wise L, Roddam A, et al. Menopausal hormone therapy and risk of gastrointestinal cancer: Nested casecontrol study within a prospective cohort, and meta-analysis. Int J Cancer 2012;130:2387-96.

34. Nanda K, Bastian L, Hasselblad V \& Simel DL. Hormone replacement therapy and the risk of colorectal cancer: a meta-analysis. Obstet Gynecol 1999;93:880-8.

35. Baan R, Straif K, Grosse Y, Secretan B, El Ghissassi F, Bouvard V, et al. Carcinogenicity of alcoholic beverages. Lancet Oncol 2007;8:292-3.

36. Pelucchi C, Tramacere I, Boffetta P, Negri E \& Vecchia C La. Alcohol Consumption and Cancer Risk. Nutr Cancer 2011;63:983-90. 
37. On The Evaluation Of Carcinogenic Risks To Humans: International Agency for Research on Cancer. Alcohol consumption and ethyl carbamate. IARC Monograph 2010;96.

38. Wang Y, Duan H, Yang H \& Lin J. A pooled analysis of alcohol intake and colorectal cancer. Int J Clin Exp Med 2015;8:6878-89.

39. *Fedirko V, Tramacere I, Bagnardi V, Rota M, Scotti L, Islami F, et al. Alcohol drinking and colorectal cancer risk: An overall and dose-response meta-analysis of published studies. Ann Oncol 2011;22(9):1958-72.

40. Moskal A, Norat T, Ferrari P \& Riboli E. Alcohol intake and colorectal cancer risk: a dose-response meta-analysis of published cohort studies. Int J Cancer 2007;120:664-71.

41. Blasiak J, Trzeciak A, Malecka-Panas E, Drzewoski J \& Wojewódzka M. In vitro genotoxicity of ethanol and acetaldehyde in human lymphocytes and the gastrointestinal tract mucosa cells. Toxicol Vitr 2000;14:287-95.

42. Duthie SJ. Folic acid deficiency and cancer: mechanisms of DNA instability. Br Med Bull 1999;55:578-92.

43. Zisman AL, Nickolov A, Brand RE, Gorchow A \& Roy HK. Associations Between the Age at Diagnosis and Location of Colorectal Cancer and the Use of Alcohol and Tobacco. Arch Intern Med 2006;166:629.

44. Chong VH, Telisinghe PU, Bickle I, Abdullah MS, Lim E \& Chong CF. Increasing incidence of colorectal cancer, starting at a younger age for rectal compared to colon cancer in Brunei Darussalam. Asian Pacific J Cancer Prev 2015;16:5063-7.

45. Siegel RL, Fedewa SA, Anderson WF, Miller KD, Ma J, Rosenberg PS, et al. Colorectal Cancer Incidence Patterns in the United States, 1974-2013. J Natl 
Cancer Inst 2017;109(8)

46. Austin H, Henley SJ, King J, Richardson LC \& Eheman C. Changes in colorectal cancer incidence rates in young and older adults in the United States: what does it tell us about screening. Cancer Causes Control 2014;25:191-201.

47. Park YM, Cho CH, Kim SH \& Lee JE. Alcohol intake, smoking, and colorectal adenoma. J Cancer Prev 2014;19:137-43.

48. Bongaerts BW, van den Brandt P, Goldbohm RA, de Goeij AFPM \& Weijenberg MP. Alcohol consumption, type of alcoholic beverage and risk of colorectal cancer at specific subsites. Int J Cancer 2008;123:2411-7.

49. Ferrari P, Jenab M, Norat T, Moskal A, Slimani N, Olsen A, et al. Lifetime and baseline alcohol intake and risk of colon and rectal cancers in the European prospective investigation into cancer and nutrition (EPIC). $\underline{\text { Int J Cancer }}$ 2007;121:2065-72.

50. Pedersen A. Relations between amount and type of alcohol and colon and rectal cancer in a Danish population based cohort study. Gut 2003;52:861-7.

51. Grønbaek M, Becker U, Johansen D, Tønnesen H, Jensen G \& Sørensen TI. Population based cohort study of the association between alcohol intake and cancer of the upper digestive tract. BMJ 1998;317:844-7.

52. Prescott E, Grønbaek M, Becker U \& Sørensen TI. Alcohol intake and the risk of lung cancer: influence of type of alcoholic beverage. Am J Epidemiol 1999;149:463-70.

53. Alcoholic drinks. World Cancer Research Fund International. Available from: http://www.wcrf.org/int/research-we-fund/cancer-preventionrecommendations/alcoholic-drinks Accessed Aug 32017.

54. *Zhu JZ, Wang YM, Zhou QY, Zhu KF, Yu CH \& Li YM. Systematic review 
with meta-analysis: alcohol consumption and the risk of colorectal adenoma. Aliment Pharmacol Ther 2014;40:325-37.

55. Liang PS, Chen T \& Giovannucci E. Cigarette smoking and colorectal cancer incidence and mortality: systematic review and meta-analysis. Int J Cancer 2009;124:2406-15.

56. *Tsoi KK, Pau CY, Wu WK, Chan FK, Griffiths S \& Sung JJ. Cigarette smoking and the risk of colorectal cancer: a meta-analysis of prospective cohort studies. Clin Gastroenterol Hepatol 2009;7:682-5.

57. Botteri E, Iodice S, Bagnardi V, Raimondi S, Lowenfels AB \& Maisonneuve P. Smoking and colorectal cancer: a meta-analysis. JAMA 2008;300:2765-78.

58. Johnson CM, Wei C, Ensor JE, Smolenski DJ, Amos CI, Levin B, et al. Metaanalyses of colorectal cancer risk factors. Cancer Causes Control 2013;24:1207-22.

59. Yang C, Wang X, Huang CH, Yuan WJ \& Chen ZH. Passive Smoking and Risk of Colorectal Cancer: A Meta-analysis of Observational Studies. Asia Pacific J Public Heal 2016;28:394-403.

60. Tramacere I, La Vecchia C \& Negri E. Tobacco Smoking and Esophageal and Gastric Cardia Adenocarcinoma. Epidemiology 2011;22:344-9.

61. Zou L, Zhong R, Shen N, Chen W, Zhu B, Ke J, et al. Non-linear doseresponse relationship between cigarette smoking and pancreatic cancer risk: Evidence from a meta-analysis of 42 observational studies. Eur J Cancer 2014;50:193-203.

62. Durko L, Malecka-Panas E. Lifestyle modifications and colorectal cancer. Curr Colorectal Cancer Rep 2014;10:45-54.

63. Leufkens AM, Van Duijnhoven FJB, Siersema PD, Boshuizen HC, Vrieling A, 
Agudo A, et al. Cigarette smoking and colorectal cancer risk in the European Prospective Investigation into Cancer and Nutrition study. $\underline{\text { Clin Gastroenterol }}$ Hepatol 2011;9:137-44.

64. *Cheng J, Chen Y, Wang X, Wang J, Yan Z, Gong G, et al. Meta-analysis of prospective cohort studies of cigarette smoking and the incidence of colon and rectal cancers. Eur J Cancer Prev 2015;24:6-15.

65. Nguyen SP, Bent S, Chen YH \& Terdiman JP. Gender as a risk factor for advanced neoplasia and colorectal cancer: a systematic review and metaanalysis. Clin Gastroenterol Hepatol 2009;7:676-681-e3.

66. Grady WM \& Carethers JM. Genomic and Epigenetic Instability in Colorectal Cancer Pathogenesis. Gastroenterology 2008;135:1079-99.

67. *Chen K, Xia G, Zhang C \& Sun Y. Correlation between smoking history and molecular pathways in sporadic colorectal cancer: a meta-analysis. Int J Clin Exp Med 2015;8:3241-57.

68. Drew DA, Nishihara R, Lochhead P, Kuchiba A, Qian ZR, Mima K, et al. A Prospective Study of Smoking and Risk of Synchronous Colorectal Cancers. Am J Gastroenterol 2017;112:493-501.

69. *Botteri E, Iodice S, Raimondi S, Maisonneuve P \& Lowenfels AB. Cigarette Smoking and Adenomatous Polyps: A Meta-analysis. Gastroenterology 2008;134: 388-95.

70. Onega T, Goodrich M, Dietrich A \& Butterly L. The influence of smoking, gender, and family history on colorectal adenomas. J Cancer Epidemiol $2010 ; 509347$

71. Purdue MP, Mink PJ, Hartge P, Huang WY, Buys S \& Hayes RB. Hormone replacement therapy, reproductive history, and colorectal adenomas: data from 
the Prostate, Lung, Colorectal and Ovarian (PLCO) Cancer Screening Trial. Cancer Causes Control 2005;16:965-73.

72. Chen MJ, Longnecker MP, Morgenstern H, Lee ER, Frankl HD \& Haile RW. Recent use of hormone replacement therapy and the prevalence of colorectal adenomas. Cancer Epidemiol Biomarkers Prev 1998;7:227-30.

73. Wu K, Willett WC, Fuchs CS, Colditz GA \& Giovannucci EL. Calcium intake and risk of colon cancer in women and men. J Natl Cancer Inst 2002;94:43746.

74. Wallace K, Grau MV, Ahnen D, Snover DC, Robertson DJ, Mahnke D, et al. The association of lifestyle and dietary factors with the risk for serrated polyps of the colorectum. Cancer Epidemiol Biomarkers Prev 2009;18:2310-7.

75. Burnett-Hartman AN, Passarelli MN, Adams SV, Upton MP, Zhu LC, Potter JD, et al. Differences in epidemiologic risk factors for colorectal adenomas and serrated polyps by lesion severity and anatomical site. Am J Epidemiol 2013;177:625-37.

76. Sansbury LB, Wanke K, Albert PS, Kahle L, Schatzkin A, Lanza E, et al. The Effect of Strict Adherence to a High-Fiber, High-Fruit and -Vegetable, and Low-Fat Eating Pattern on Adenoma Recurrence. Am J Epidemiol 2009;170:576-84.

77. Anderson AS, Craigie AM, Caswell S, Treweek S, Stead M, Macleod M, et al. The impact of a bodyweight and physical activity intervention (BeWEL) initiated through a national colorectal cancer screening programme: randomised controlled trial. BMJ 2014;348:g1823.

78. Todd A, Moore HJ, Husband AK, Bambra C, Kasim A, Sniehotta FF, et al. Community Pharmacy Interventions for Public Health Priorities: Protocol for a 
Systematic Review of Community Pharmacy-Delivered Smoking, Alcohol and Weight Management Interventions. Syst Rev 2014;3:93.

79. Panda R, Persai D \& Venkatesan S. Missed opportunities for brief intervention in tobacco control in primary care: patients' perspectives from primary health care settings in India. BMC Health Serv Res 2015;15:50.

80. Diaz Gomez C, Ngantcha M, Le Garjean N, Brouard N \& Lasbleiz M, Perennes M, et al. Effect of a brief motivational intervention in reducing alcohol consumption in the emergency department. Eur J Emerg Med 2017;1; Epub Jul 12.

81. International Agency for Research on Cancer, World Health Organisation. Globocan 2012; 2012. Accessed from: http://globocan.iarc.fr/Default.aspx 
Figure Legends.

Figure 1. Current classification of epithelial colorectal polyps.

Figure 2. Worldwide colorectal incidence (age-standardised rates per 100 000) in Men (A) and Women (B) [81]. 
Table 1. Summary of evidence for association between alcohol and colorectal neoplasms

\begin{tabular}{|c|c|c|c|c|}
\hline Neoplasm & $\begin{array}{l}\text { Direction of } \\
\text { association }\end{array}$ & Strength of association & Related notable findings & $\begin{array}{l}\text { Key } \\
\text { References* }\end{array}$ \\
\hline Carcinoma & Positive & $\begin{array}{l}\text { Any v. non/occasional } \\
\text { drinking } \\
\text { RR } 1.13 \text { (95\% CI 1.09-1.17) }\end{array}$ & $\begin{array}{l}\text { Dose-response associations for light, moderate } \\
\text { and heavy drinking. }\end{array}$ & {$[38]$} \\
\hline Adenoma & Positive & $\begin{array}{l}\text { Any v. non-drinking } \\
\text { RR } 1.17 \text { (95\% CI 1.11-1.22) }\end{array}$ & $\begin{array}{l}\text { Dose-response associations for light, moderate } \\
\text { and heavy drinking. } \\
\text { Associations were weaker in nested case-control } \\
\text { studies. } \\
\text { Associations were stronger in European studies } \\
\text { compared with US/Asia studies. }\end{array}$ & {$[54]$} \\
\hline $\begin{array}{l}\text { Serrated } \\
\text { Polyps }\end{array}$ & Positive & $\begin{array}{l}\text { High v. low alcohol drinking } \\
\text { RR } 1.33 \text { (95\% CI 1.17-1.52) }\end{array}$ & $\begin{array}{l}\text { Association was stronger for sessile serrated } \\
\text { lesions compared with hyperplastic polyps and } \\
\text { traditional serrated adenomas. }\end{array}$ & {$[2]$} \\
\hline
\end{tabular}

RR: Relative Risk. CI: Confidence Intervals. *References pertain to the risk estimates shown in the most recently published meta-analyses. Further studies are referenced in the relevant corresponding text of the review. 
Table 2. Summary of evidence for association between smoking and colorectal neoplasms

\begin{tabular}{|c|c|c|c|c|}
\hline Neoplasm & $\begin{array}{l}\text { Direction of } \\
\text { association }\end{array}$ & Strength of association & Related notable findings & $\begin{array}{l}\text { Key } \\
\text { References* }\end{array}$ \\
\hline Carcinoma & Positive & $\begin{array}{l}\text { Current v. never smoking } \\
\text { RR } 1.38 \text { (95\% CI 1.22-1.56) }\end{array}$ & $\begin{array}{l}\text { Dose-response association observed. } \\
\text { Smoking is related to specific molecular subtypes, } \\
\text { proximal colon and rectal location of tumours. }\end{array}$ & {$[56]$} \\
\hline Adenoma & Positive & $\begin{array}{l}\text { Current v. never smoking } \\
\text { RR } 2.14 \text { (95\% CI 1.86-2.46) }\end{array}$ & Association appears more pronounced in men. & [69] \\
\hline $\begin{array}{l}\text { Serrated } \\
\text { Polyps }\end{array}$ & Positive & $\begin{array}{l}\text { High v. low smoking } \\
\text { exposure } \\
\text { RR } 2.47 \text { (95\% CI } 2.12-2.87)\end{array}$ & $\begin{array}{l}\text { Association was stronger for sessile serrated lesions } \\
\text { (RR 3.40; 95\% CI 1.90-6.07) than hyperplastic } \\
\text { polyps (RR 2.34; 95\% CI 2.00-2.73) }\end{array}$ & {$[2]$} \\
\hline
\end{tabular}

RR: Relative Risk. CI: Confidence Intervals. *References pertain to the risk estimates shown in the most recently published meta-analyses. Further studies are referenced in the relevant corresponding text of the review. 
Figure 1

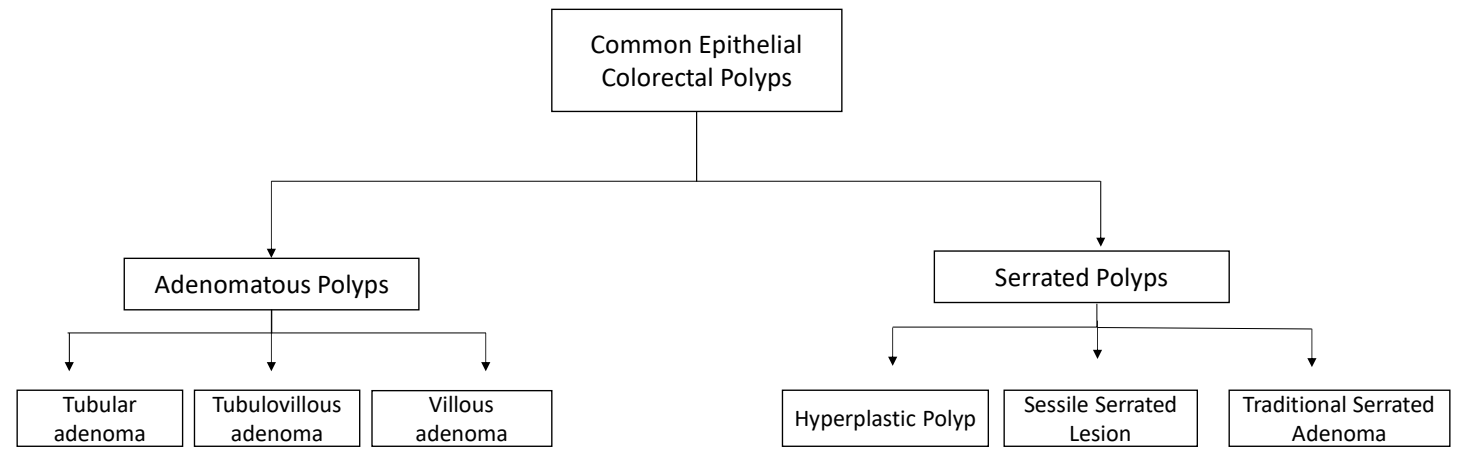


Figure 2.

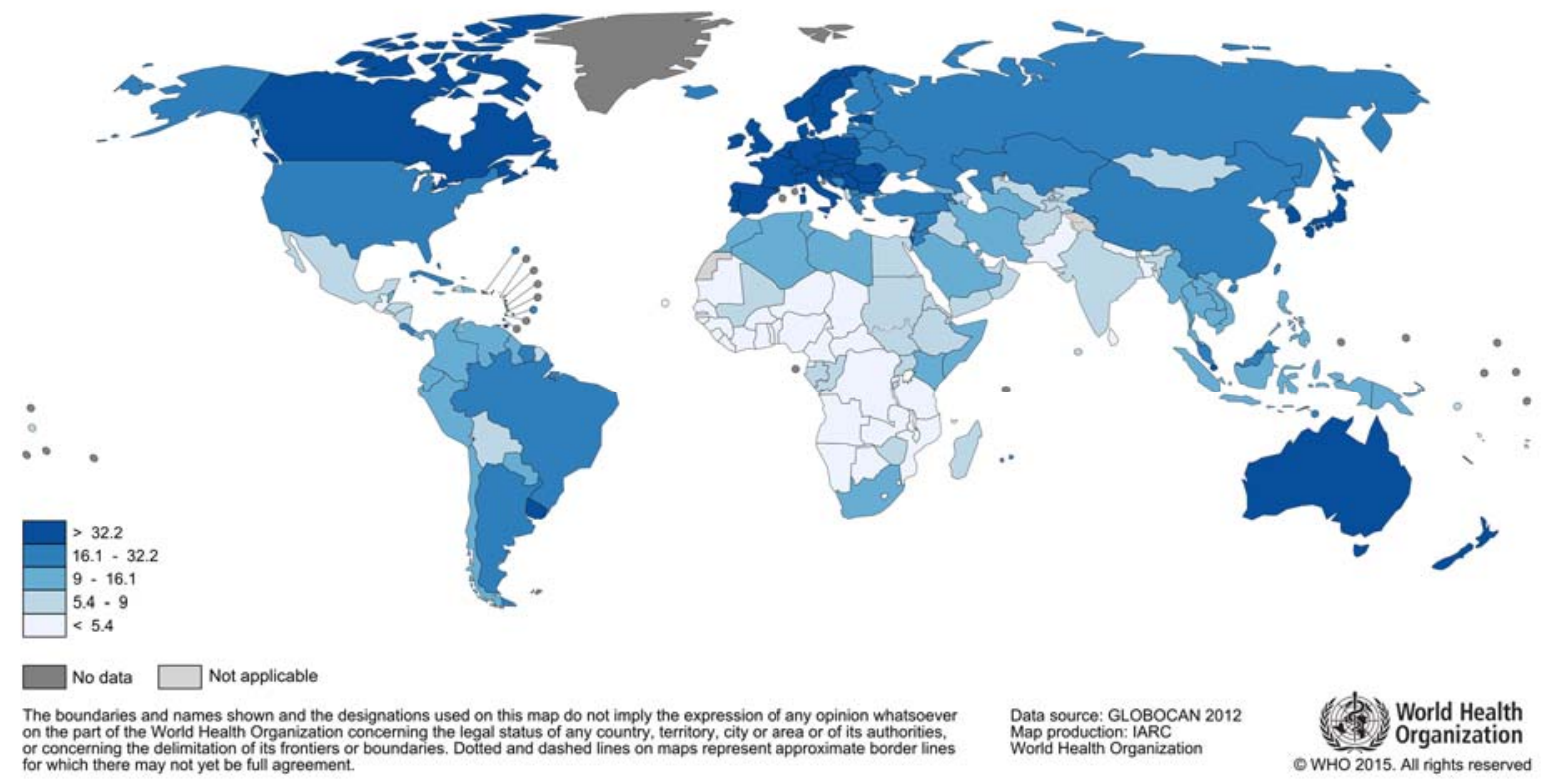

(A)

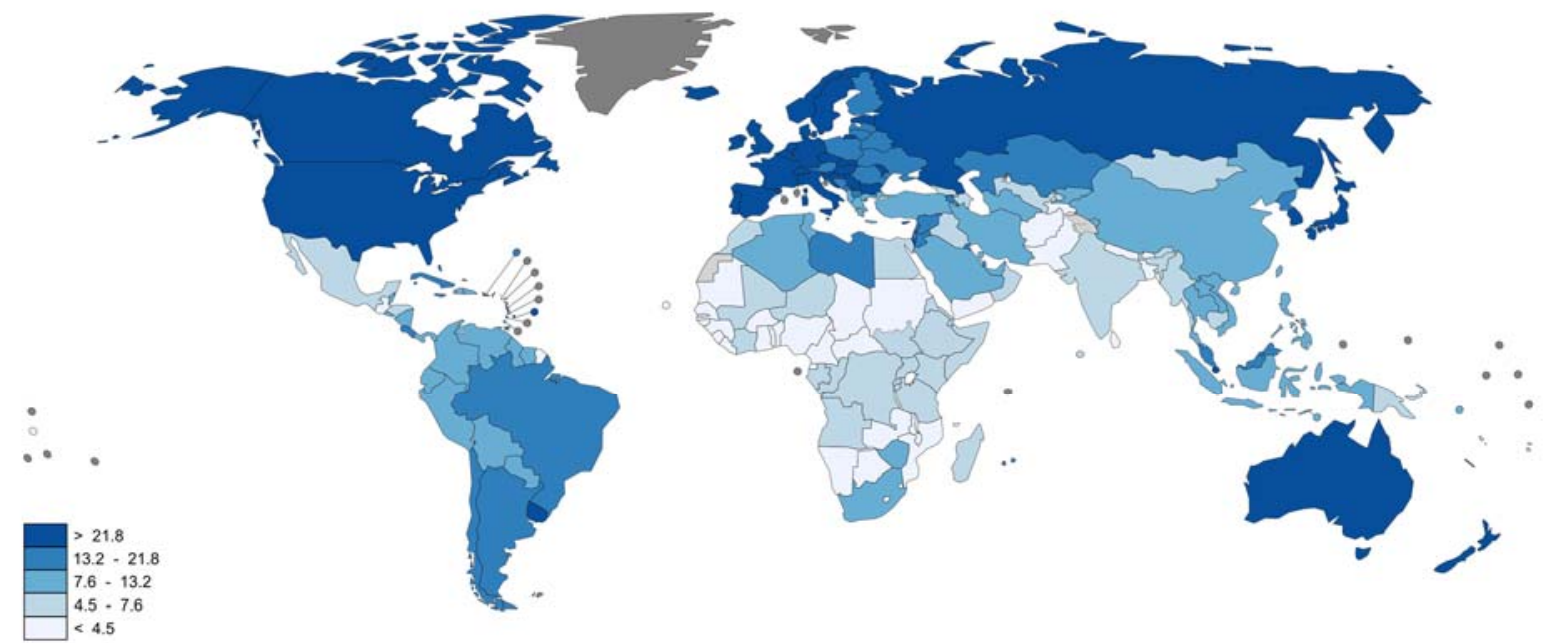

$\square$ No data $\square$ Not applicable

The boundaries and names shown and the designations used on this map do not imply the expression of any opinion whatsoever
on the part of the World Heatth Organization concerning the legal status of any country, territory, city of area or of its authorities.
Map production: IARC 2012 $\begin{array}{ll}\text { on the part of the World Health Organization concerning the legal status of any country, territory, city or area or of its authorities, } & \text { Map production: IARC } \\ \text { or concerning the delimitation of its frontiers or boundaries. Dotted and dashed lines on maps represent approximate border lines } & \text { World Health Organization }\end{array}$

Werld Health or which there may not yet be full agreement.

(B) 